\title{
Using Opioid Analgesics to Manage Chronic Noncancer Pain in Primary Care
}

Tom Parrott, $M D$

Background: Opioid analgesics have been considered the drugs of choice for the treatment of moderate to severe cancer and postoperative pain. Cultural attitudes and concerns about abuse have inhibited their use for a larger population of patients who have chronic noncancer pain.

Methods: Medical literature was searched from 1990 to 1998 using the key words "opioid analgesics," "opioid abuse," and "chronic pain." I have also drawn from more than 20 years of experience prescribing opioid analgesics for chronic pain. A case series analysis of $\mathbf{3 0}$ patients using opioid analgesics for periods ranging from 6 months to 17 years was performed.

Results and Conclusions: The World Health Organization has published a "three-step ladder" guide to treatment of cancer pain graded from mild to severe; this guide can be readily applied to the treatment of pain from all sources. Opioid analgesics are the mainstay of treatment for moderate to severe pain. Chronic pain patients offer some difficult challenges for busy primary care physicians. The unique pharmacologic characteristics of opioid medications are important in outpatient management. A four-sheet office management protocol helps to focus efficiently on important clinical issues related to pain control, to monitor for opiate abuse, and to incorporate pain management more effectively in the overall primary care plan of the patient. (J Am Board Fam Pract 1999;12:293-306.)

Pain of all types is among the most frequent chief complaints physicians encounter in primary care specialties. ${ }^{1}$ One of the greatest challenges primary care physicians face is to provide effective treatment for chronic pain. Chronic pain (also called persistent pain) is defined as pain that lasts longer than 6 months. ${ }^{1}$ Pain can derive from many sources including cancer. Noncancer pain refers to pain from any other source, such as illness, injury, or postoperative changes. In my practice, noncancer chronic pain is a far more frequent problem than pain from cancer. Noncancer pain often derives from sources that are equally incurable and can in many instances produce pain in the moderate to severe range, which can not only dominate the lives of patients but can also be incapacitating. A recent review of the treatment of all forms of chronic pain urged health care providers to be as effective as possible in treating pain without making value judgments regarding its source. ${ }^{2}$ Certainly patients in chronic pain

Submitted, revised, 24 August 1998.

From the White River Family Practice, White River Junction, Vermont. Address reprint requests to Tom Parrott, $M D$, 331 Olcott Dr, White River Junction, VT 05001. from a noncancer source are no less deserving of effective pain control than those whose pain derives from cancer.

\section{Methods}

The medical literature was searched from 1990 to 1998 using the key words "opioid analgesics," "opioid abuse," and "chronic pain." I have drawn on my own personal experience in office practice of prescribing opioid analgesics for patients in chronic pain for more than 20 years, and I performed a case series analysis of 30 patients using opioid analgesics for periods ranging from 6 months to 17 years.

\section{Chronic Pain in Primary Care}

The World Health Organization (WHO) recently published results of a survey of 25,916 primary care patients in 14 different countries. ${ }^{1}$ This survey found that 21.5 percent of primary care patients (16.2 percent of men and 24.8 percent of women) had experienced severe pain for most of a 6-month period during the previous year. The anatomical sites for the pain (68 percent had pain at two sites) mentioned in decreasing order of frequency were back, head, joints, extremity, chest, 


\section{FREEDOM FROM PAIN}

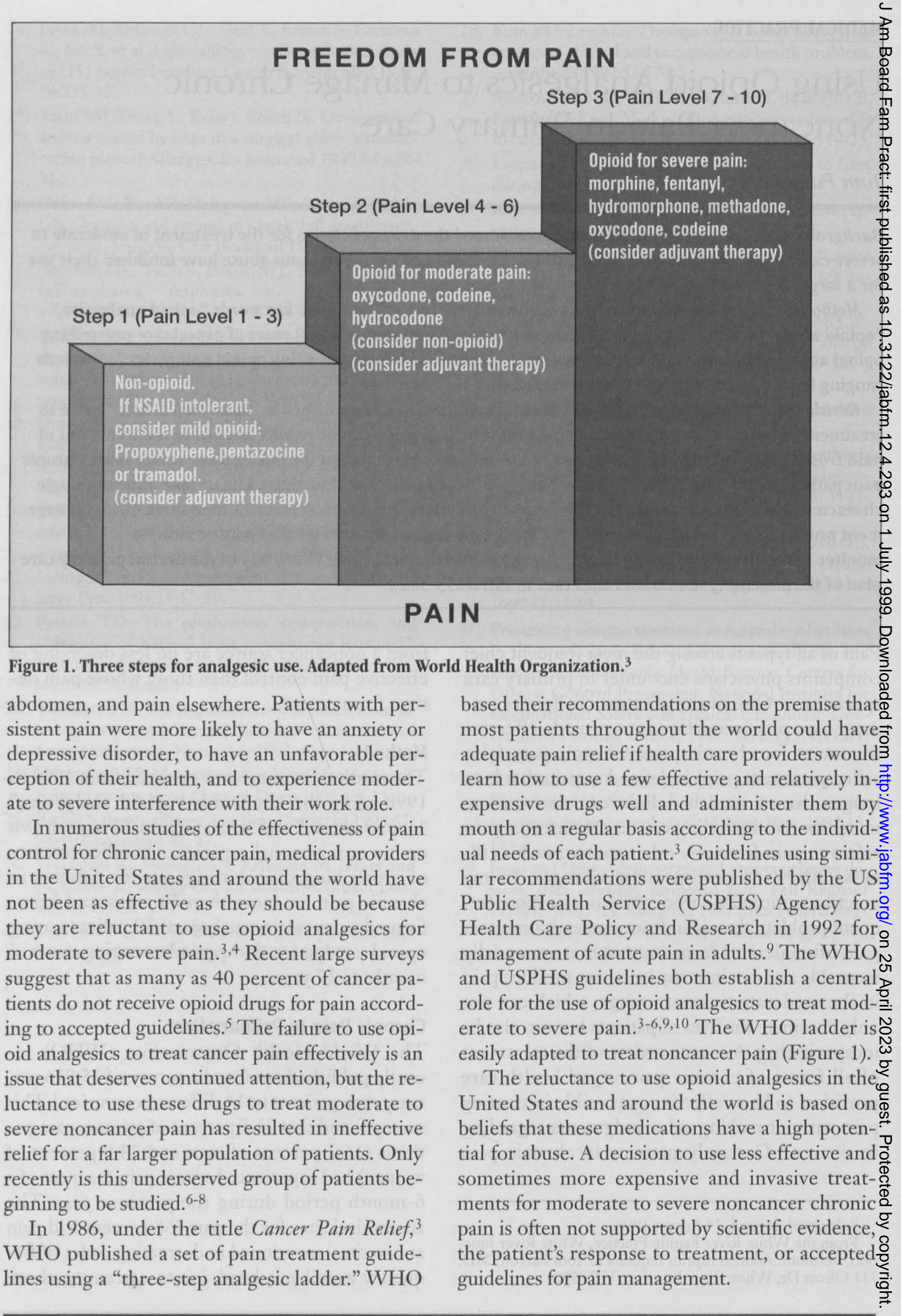




\section{Pharmacology of Opioid Analgesics}

Some clinicians believe that opioid analgesics exert their action only on the brain and that their pain-relieving properties are linked to their sedative effects. This mode of action is less acceptable culturally than is that of nonsteroidal anti-inflammatory drugs (NSAIDs), which are thought to play their most important role at the peripheral source of the pain. Recent research has shown that systemically inactive low doses of intra-articular morphine can significantly reduce pain after knee surgery through stimulation of peripheral opioid receptors. ${ }^{11}$ This and other research has led to an expanded understanding of the mechanism of action of opioid analgesics.

Systemically delivered opioid analgesics do produce analgesia through actions in the brain. This effect is based on stimulation of $\mu, \delta$, and $\kappa$ opioid receptors and receptor-selective opioid peptides that are concentrated in several sites. Injection of opioid analgesics at the level of the spinal cord also produces highly effective analgesia and is the basis for their effectiveness to relieve labor pain, postoperative pain, and cancer pain. ${ }^{12}$

Pain is modified by endogenous opioids (endorphins and metenkephalin) found in both central nervous system and peripheral tissue. ${ }^{13}$ This issue is important to both patients and health care providers who hope to enhance the patient's ability to cope with chronic pain with lower doses of exogenous opioid analgesics. The release of endogenous opioids is thought to be an important mechanism through which aerobic exercise and behavioral and relaxation techniques help in the treatment of chronic pain. ${ }^{14}$

Natural and synthetic opioid analgesics, a class of medication widely considered to offer the drugs of choice for severe acute pain and chronic cancer pain, ${ }^{15}$ have several unique characteristics. Oral codeine, propoxyphene, and pentazocine, when taken alone in usual doses, are no more effective than aspirin or acetaminophen. ${ }^{15}$ These opioid analgesics are often combined with aspirin or acetaminophen to treat moderate pain. Morphine, hydromorphone, methadone, levorphanol, fentanyl, and large doses of oxycodone are used for more severe pain. ${ }^{15}$ Tramadol (for which there is no generic equivalent) is a centrally acting analgesic that binds to $\mu$ opioid receptors. The analgesic efficacy of tramadol is considered to be equivalent to $30 \mathrm{mg}$ of codeine plus $650 \mathrm{mg}$ of acetaminophen ${ }^{10}$

Tolerance is a unique problem with opioid analgesics. The patient first notices a shorter duration of analgesia and then an increase in pain. In my experience, this problem has occurred in a minority of patients experiencing the most severe pain. For these few patients requiring very high doses of oral medication, tolerance presents practical problems of prescribing multiple pill doses (eg, $5 \mathrm{mg}$ of oxycodone, unavailable in larger dose tablets in an inexpensive generic form). Recommended doses (Tables 1 and 2) should be given in formulations (short vs long acting) when they will be most useful for pain relief and allow patients to optimize normal function. Normally the mildest agents are prescribed first, reserving the strongest agents for the most intractable pain. Using the WHO ladder approach, the dose will often need to be titrated, especially for patients experiencing moderate to severe pain. Experts have pointed out that "there is no one optimal or maximal dose of a step 3 opioid analgesic drug. The appropriate dose is one that relieves a patient's pain throughout its dosing interval without causing unmanageable side effects." ${ }^{10}$ Many chronic pain patients have other chronic illnesses, and interaction of opioid analgesics with other medications will need to be considered.

Tolerance can be delayed by giving nonopioid analgesics and adjuvant therapy (eg, tricyclic antidepressants) concurrently. ${ }^{10}$ Tolerance to most adverse effects of opioid analgesics, including respiratory and central nervous system depression, develops at least as rapidly as the analgesic effect. Cross-tolerance exists among all full agonists, but it is not complete, and starting with one half the dose when switching to another opioid agonist is advised. Switching to a partial agonist or a mixed agonist-antagonist can precipitate withdrawal in a patient whose pain has been treated with one of the morphine- or codeine-related or synthetic agonists. ${ }^{15}$

Constipation, sedation, dizziness, nausea, and vomiting are the most common adverse effects of opioid analgesics. Sedation can be ameliorated by decreasing the dose and increasing the frequency of administration or by switching to opioid analgesics with a shorter half-life. ${ }^{15}$ Detailed suggestions regarding the management of constipation (which is the most frequent side effect with 
Table 1. Starting Dosages and Costs of Selected Opioid Analgesics for Moderate to Severe Pain (Outpatient Medications: WHO Ladder Step 3) in Decreasing Order of Effectiveness and Physical Dependency.

\begin{tabular}{|c|c|c|c|}
\hline \multirow[b]{2}{*}{ Opioid Analgesic (Brand name) } & \multirow{2}{*}{$\begin{array}{l}\text { Equianalgesic } \\
\text { Oral 24-h Dosage }\end{array}$} & \multicolumn{2}{|c|}{ Estimated Wholesale Cost for 30 Days of Therapy ${ }^{16}$} \\
\hline & & Generic & Brand Name \\
\hline Morphine tablets (MSIR) & $180-240 \mathrm{mg}$ & $\begin{array}{c}\$ 41-\$ 55 \\
(30 \mathrm{mg}, 6-8 / \mathrm{d})\end{array}$ & $\begin{array}{c}\$ 115-\$ 154 \\
(30 \mathrm{mg}, 6-8 / \mathrm{d})\end{array}$ \\
\hline Morphine sustained release (MS Contin) & $180-240 \mathrm{mg}$ & Not available & $\begin{array}{c}\$ 302-\$ 402 \\
(60 \mathrm{mg}, 3-4 / \mathrm{d})\end{array}$ \\
\hline Fentanyl patch (Duragesic) & $50-75 \mu \mathrm{g} / \mathrm{h}$ & Not available & $\begin{array}{c}\$ 162-\$ 247 \\
(50-75 \mu \mathrm{g} / \mathrm{h} \text { patch } / 72 \mathrm{~h})\end{array}$ \\
\hline Meperidine tablets (Demerol) & Not recommended ${ }^{*}$ & - & - \\
\hline Hydromorphone tablets (Dilaudid) & $45-60 \mathrm{mg}$ & $\begin{array}{c}\$ 150-\$ 200 \\
(4 \mathrm{mg}, 11-15 / d)\end{array}$ & $\begin{array}{c}\$ 180-\$ 300 \\
(8 \mathrm{mg}, 5-8 / \mathrm{d})\end{array}$ \\
\hline Methadone tablets & $60-80 \mathrm{mg}$ & $\begin{array}{c}\$ 15-\$ 20 \\
(40 \mathrm{mg}, 1.5-2 / \mathrm{d})\end{array}$ & No brand name listed ${ }^{16}$ \\
\hline Butorphanol nasal spray (Stadol NS) & $\begin{array}{c}6-12 \mathrm{mg} \\
(1 \mathrm{mg} / \mathrm{spray})^{17}\end{array}$ & Not available & $\begin{array}{l}\$ 450-\$ 900 \\
(6-12 \text { spray/d })^{\dagger}\end{array}$ \\
\hline $\begin{array}{l}\text { Oxycodone tablets (without acetaminophen } \\
\text { or acetylsalicylic acid) }\end{array}$ & $60-80 \mathrm{mg}$ & $\begin{array}{c}\$ 120-\$ 150 \\
(5 \mathrm{mg}, 12-16 / \mathrm{d})\end{array}$ & $\begin{array}{l}\text { No brand name without } \\
\text { acetaminophen or } \\
\text { acetylsalicylic acid }\end{array}$ \\
\hline Long-acting oxycodone tablets (Oxy Contin) & $60-80 \mathrm{mg}$ & Not available & $\begin{array}{c}\$ 180-\$ 240 \\
(40 \mathrm{mg}, 1.5-2 / \mathrm{d})\end{array}$ \\
\hline Codeine $60-\mathrm{mg}$ tablets & $360-480 \mathrm{mg}$ & $\begin{array}{c}\$ 210-\$ 270 \\
(60 \mathrm{mg}, 6-8 / \mathrm{d})\end{array}$ & No brand name listed ${ }^{16}$ \\
\hline
\end{tabular}

Adapted from Montauk and Martin, ${ }^{2}$ Table 7: "Dose Equivalents for Opioid Analgesics in Opioid Naive Adults and Children Who Weigh at Least $50 \mathrm{~kg}$." Published tables vary in suggested equianalgesic starting doses. Titration to effective clinical response is needed *Equianalgesic oral dose would be $2400-3600 \mathrm{mg} / 24 \mathrm{~h}$. Intravenous or intramuscular doses only are recommended for severe pain.

${ }^{\dagger}$ Mode of administration and price could make butorphanol impractical for chronic use.

‡Acetaminophen content of combined preparations risks toxicity with high doses in chronic use.

chronic use) are published elsewhere. ${ }^{2}$

All patients who take opioid analgesics will develop some degree of physical dependence and will develop withdrawal symptoms if the drug is withdrawn suddenly. Patients who take opioid analgesics for acute pain or cancer pain rarely experience euphoria and even more rarely develop psychic dependence or addiction to the mood-altering effects of narcotics. ${ }^{15}$ A 1996 review of case studies in which opioid analgesics were used to treat chronic noncancer back pain found that abuse behaviors occurred in less than 5 percent of 566 patients treated during periods ranging from 6 months to approximately 16 years. ${ }^{6}$ The degree of physical dependence is directly proportional to the strength and effectiveness of the opioid analgesic being used.

Symptoms of withdrawal include intense desire for drugs, muscle cramps, arthralgia, anxiety, nausea, vomiting, and malaise. Signs of withdrawal include drug-seeking behavior, mydriasis, piloerection, diaphoresis, rhinorrhea, lacrimation, diarrhea, insomnia, and mild elevation of blood pressure and pulse rate. ${ }^{18}$ These symptoms and signs would typically be observed during withdrawal from the use of intravenous heroin. With long-term use of oral opioid analgesics, it is common for patients to run out of medication from time to time. Even in patients taking high doses of oral medications, the withdrawal symptoms are described as mild, especially when compared with the suffering caused by return of pain.

Opioid analgesic detoxification protocols using clonidine or methadone are available. ${ }^{18} \mathrm{It}$ is important to note that federal regulations allow the use of methadone for opioid detoxification only at facilities designated for this purpose if opioid analgesic withdrawal is the primary diagnosis. Methadone may be used for withdrawal, however, if the primary diagnosis is a medical condition and the secondary condition is withdrawal from opioid analgesics. ${ }^{18}$

The US Drug Enforcement Administration has established schedules for opioid medications. The lower the schedule number, the more powerful the opioid analgesic. Schedules for commonly 
Table 2. Recommended Dosages and Cost of Selected Opioid Analgesics for Mild to Moderate Pain (Outpatient Medications: WHO Ladder: Step 2).

\begin{tabular}{|c|c|c|c|}
\hline \multirow[b]{2}{*}{ Opioid Analgesic (Brand Name) } & \multirow{2}{*}{$\begin{array}{l}\text { 24-h Dosages for Mild } \\
\text { to Moderate Pain }\end{array}$} & \multicolumn{2}{|c|}{ Estimated 30-day Wholesale Cost of Therapy ${ }^{16}$} \\
\hline & & Generic & Brand Name \\
\hline Codeine 30 -mg tablets & $120-240 \mathrm{mg}$ & $\begin{array}{c}\$ 60-\$ 106 \\
(30 \mathrm{mg}, 4-6 / d)\end{array}$ & No brand names listed ${ }^{16}$ \\
\hline $\begin{array}{l}\text { Hydrocodone tablets } \\
\text { (with acetaminophen }{ }^{\star} \text { ) (Lorcet) }\end{array}$ & $10-60 \mathrm{mg}$ & $\begin{array}{c}\$ 20-\$ 83 \\
(5 \mathrm{mg}, 2-12 / \mathrm{d})\end{array}$ & $\begin{array}{c}\$ 23-\$ 135 \\
(10 \mathrm{mg}, 1-6 / \mathrm{d})\end{array}$ \\
\hline $\begin{array}{l}\text { Pentazocine tablets (with } \\
\text { naloxone }{ }^{\dagger} \text { ) (Talwin NX) }\end{array}$ & $200-300 \mathrm{mg}$ & $\begin{array}{c}\$ 98-\$ 148 \\
(50 \mathrm{mg}, 4-6 / \mathrm{d})\end{array}$ & $\begin{array}{l}\$ 110-\$ 166 \\
(4-6 / d)\end{array}$ \\
\hline Propoxyphene capsules (Darvon) & $260-780 \mathrm{mg}$ & $\begin{array}{c}\$ 36-\$ 108 \\
(65 \mathrm{mg}, 4-12 / \mathrm{d})\end{array}$ & $\begin{array}{c}\$ 50-\$ 131 \\
(4-12 / d)\end{array}$ \\
\hline $\begin{array}{l}\text { Propoxyphene napsylate tablets } \\
\text { (with acetaminophen }^{\star} \text { ) (Darvocet) }\end{array}$ & $400-600 \mathrm{mg}$ & $\begin{array}{c}\$ 36-\$ 54 \\
(100 \mathrm{mg}, 4-6 / d)\end{array}$ & $\begin{array}{l}\$ 78-\$ 117 \\
(4-6 / d)\end{array}$ \\
\hline Tramadol tablets (Ultram) & $200-400 \mathrm{mg}$ & Not available & $\begin{array}{c}\$ 74-\$ 149 \\
(4-8 / d)\end{array}$ \\
\hline
\end{tabular}

Adapted from Montauk and Martin, ${ }^{2}$ Table 5 - WHO Guidelines for Chronic Pain Management - Step 2.

"Acetaminophen content of combined products risks toxicity with high doses in chronic use.

tCombined with naloxone, a narcotic antagonist to prevent parenteral pentazocine abuse. Oral naloxone can produce withdrawal symptoms in patients receiving morphine or codeine agonists.

used opioid analgesics are as follows: Tramadol is unscheduled. Schedule IV medications are propoxyphene and pentazocine. Schedule III medications are hydrocodone and codeine $30 \mathrm{mg}$. (Schedule IV and III medications are considered less addicting and the prescriptions can be called in). Schedule II medications (which are considered more addicting, need a written prescription, and are limited by state law to a total number of pills per prescription) include codeine $60 \mathrm{mg}$, oxycodone, methadone, hydromorphone, meperidine, fentanyl, and morphine.

Adjunctive pharmacotherapies include NSAIDs, antidepressant medications, and antiseizure drugs. NSAIDs are the mainstay of treatment for most patients experiencing mild chronic pain (Figure 1: WHO ladder, step 1) and can be used when appropriate as adjuncts for moderate to severe pain as well. A mild opioid analgesic, such as codeine, hydrocodone, propoxyphene, pentazocine, or tramadol, might be better tolerated for continuous use in the elderly or other patients for whom NSAID toxicity is an issue. Because anxiety and depression commonly accompany chronic pain, antidepressants can play an important role. Desipramine, nortriptyline, and trazodone, rather than amitriptyline, are preferred because of their superior side effect profile. Selective serotonin reuptake inhibitors have not proved beneficial for pain control thus far. A more detailed discussion of the use of these medications is available else- where. ${ }^{2,10}$ Neuropathic pain is a uniquely difficult situation, often producing pain refractory to any measures. Antidepressants or anticonvulsants should be considered for this type of pain because they can improve the quality of sleep and alter pain thresholds. ${ }^{10}$

The selection of opioid analgesic is influenced by (1) the type, location, and cause of pain (eg, headache, inflammation, post-traumatic, abdominal-pelvic, neuropathic, etc); (2) how long during the night or day the pain is active, and which of the patient's activities are influenced by pain; (3) associated medical and psychologic conditions; (4) how well the opioid analgesic relieves pain, and what, if any, undesirable side effects it produces; and (5) the complex emotional and social context in which the patient, the patient's family, and the medical care system view this type of medication.

\section{Opioid Analgesic Abuse}

Drug abuse is defined in several ways. The $\mathrm{Na}$ tional Institute on Drug Abuse considers drug abuse to occur when psychoactive medication (prescribed or nonprescribed) is used for nonmedical reasons, ie, to become high (stimulated, intoxicated, or euphoric)..$^{19}$ According to the $1990 \mathrm{Na}$ tional Household Survey on Drug Abuse, opioid analgesics were used at least once for nonmedical purposes during the previous year by fewer than 4 percent of the respondents. The number of times respondents reported that they had experienced 
problems related to nonmedical analgesic use, such as feelings of depression, isolation, and irritability, or whose drug use had caused problems with their health, work, or school activities was "too infrequent to yield reliable estimates." ${ }^{19}$ It appears that in American society at large, problems related to abuse or the nonmedical use of prescription opioid analgesics are too few to attain statistical significance.

Monitoring patient drug use can be difficult. Patient behavior patterns in a given population are influenced by such factors as population mobility; average educational, age, and economic levels; incidence of drug abuse and criminal activity in the community; and access to and quality of relationships with their primary care and other medical providers.

I practice in a suburban to rural environment in northern New England. The size of the service area population, roughly 25,000 , facilitates close communication and follow-up with pharmacists in the community as well as with police and regulatory agencies responsible for investigation of drug diversion.

Characteristic patient behaviors that suggest the possibility of opiate intoxication or diversion would be the following: (1) obtaining opioid analgesic prescriptions from more than one provider or pharmacy; (2) appearing intoxicated to family members or co-workers when arriving for office appointments or when encountered in the community; (3) arrests for driving while under the influence of a drug or alcohol; (4) repeatedly losing an opioid medication (or having it stolen) and then requesting refills from the physician on call or physicians in emergency departments or urgent care facilities; and (5) any illegal activities (selling the drugs, distributing them for recreational or nonmedical use, altering or forging prescriptions, etc.). As is the case with alcoholism, a family member or close friend, if the patient lives alone, is an invaluable source of information about adverse effects of the medication.

Recent guidelines for physicians prescribing opioid analgesics have been issued by the Federation of State Medical Boards. ${ }^{20}$ The federation recommends that state boards consider several guidelines when evaluating a physician's prescribing practices:

1. Findings from a complete history and physical examination should be in the patient's medical record. The record should include details about the intensity of the pain, current and past pain treatments, the effect of pain on physical and psychologic functioning, and history of substance abuse.

2. The record should have the patient's treatment plan, including ways to measure response to treatment for pain. Treatment with modalities other than analgesics and treatment for other medical and psychosocial conditions should be mentioned.

3. The physician should document a discussion with the patient of the risks and benefits of treatment of pain with controlled substances (obtain an informed consent). Expectations for appropriate blood and urine tests should be documented. A contract or written agreement describing dosage of opioids, frequency of visits, and number of prescription refills is recommended.

4. The physician should see the patient at appropriate intervals.

5. Consultations with other specialists (eg, pain treatment specialists, mental health experts) should occur as appropriate.

6. The record should contain medications prescribed (date, type, dose, and quantity) and follow-up visits planned.

7. The physician must be licensed in the state and be in compliance with federal and state regulations. ${ }^{20}$

\section{Office Program to Use Opioid Analgesics for Noncancer Pain}

Chronic pain is similar to other chronic illnesses in many ways, and the goals for treating it are similar. Ideally, medications prescribed should be the lowest dose of the most effective, least expensive agent associated with the fewest undesirable side effects. Patients suffering from moderate to severe pain are usually very sick, and they often require more time than patients who are less symptomatic. On this account, their visits to the office can delay or interrupt the flow of regularly scheduled patients seen by family physicians.

To better meet the needs of the patients and to make rules of conduct and treatment expectations clear to my patients, office staff, and physician partners on call, I developed a simple program on 4 pages of the patient record (Figures 2 through $5)$. This program enables documentation of the 


\section{Contract for Long-Term Use of Opioid Analgesic}

You have agreed to use opioid analgesic therapy for the relief of pain. The reason(s) you have pain is (are):

The goals for using this medication are (1) to relieve suffering, (2) to improve sleep and functioning during the day, and (3) work along with other treatments to allow your body to heal as much as possible.

This class of medicines can produce the following adverse effects: drowsiness, nausea, confusion, constipation, tolerance (requires more and more of the medicine to provide the same amount of pain relief), physical dependence (a withdrawal syndrome might occur when you stop using it), increased sensitivity to all pain, and addiction (loss of control over the amount of medicines used, constantly seeking more medicine, and adverse effects on important portions of your life).

Prescribing this class of medicines is regulated by state and federal law. It is very important that you agree to the following guidelines:

I will obtain medication from only one physician:

If my regular physician is not available, I will contact the physician from White River Family Practice who is on call and explain the circumstances. I might be asked to come in for evaluation. Normally only enough medication to last until my next appointment with my regular physician will be prescribed. If my pain can be controlled with rest and other measures for a few days, that is far better than asking for an "emergency supply." I will not visit the emergency department for pain medication.

I will purchase my prescriptions from only one pharmacy:

I agree that this pharmacy will have a copy of this contract so that the pharmacist is clear on what to expect. If I use other physicians or pharmacies to obtain opioid analgesic medication, it could result in discontinuation of all treatment from White River Family Practice. I also agree that other area pharmacies can be notified of my contract.

The opioid analgesic medications and doses will be:

The frequency of visits to the office will be:

Don't change the frequency or dose of your medication unless you check with your regular physician. If your opioid analgesic medicine is stolen, it must be reported to the police. Repeatedly lost or stolen medication or frequently missed appointments could result in discontinuation of treatment.

Signature of patient____Date

Signature of physician Date

Figure 2. Contract for long-term use of opioid analgesic medication. 


\begin{tabular}{|c|c|c|c|c|}
\hline WHO Step Characteristics & $\begin{array}{l}\text { Number } \\
\text { of } \\
\text { Patients }\end{array}$ & $\begin{array}{l}\text { Average } \\
\text { Age }(y)\end{array}$ & $\begin{array}{c}\text { Patients With } \\
\text { Additional Medical and } \\
\text { Psychologic Problems }\end{array}$ & $\begin{array}{l}\text { Patients Receiving } \\
\text { Adjuvant Therapy }\end{array}$ \\
\hline Step 1 - peak pain levels without medication $1-3^{\star}$ & 7 & 61 & $5(71 \%)$ & 0 \\
\hline \multicolumn{5}{|l|}{ Diagnoses leading to pain } \\
\hline Back pain & 5 & & & \\
\hline Degenerative arthritis & 2 & & & \\
\hline \multicolumn{5}{|l|}{ Opioid analgesics and dosages } \\
\hline Propoxyphene $130-520 \mathrm{mg} / 24 \mathrm{~h}$ & 4 & & & \\
\hline Codeine $30-60 \mathrm{mg} / 24 \mathrm{~h}$ & 2 & & & \\
\hline Oxycodone $5-10 \mathrm{mg} / 24 \mathrm{~h}$ & 1 & & & \\
\hline Step 2 - peak pain levels without medication $4-6^{\star}$ & 15 & 48 & $4(27 \%)$ & $2(13 \%)$ \\
\hline \multicolumn{5}{|l|}{ Diagnosis leading to pain } \\
\hline Back pain & 8 & & & \\
\hline Degenerative arthritis & 2 & & & \\
\hline Headaches & 2 & & & \\
\hline Neuralgia & 2 & & & \\
\hline \multicolumn{5}{|l|}{ Opioid analgesics and dosages } \\
\hline Oxycodone $10-25 \mathrm{mg} / 24 \mathrm{~h}$ & 6 & & & \\
\hline Hydrocodone $15-60 \mathrm{mg} / 24 \mathrm{~h}$ & 4 & & & \\
\hline Propoxyphene $260-520 \mathrm{mg} / 24 \mathrm{~h}$ & 4 & & & \\
\hline Codeine $240 \mathrm{mg} / 24 \mathrm{~h}$ & 1 & & & \\
\hline Step 3 - peak pain levels without medication $7-10^{\star}$ & 8 & 49 & $3(37 \%)$ & $6(75 \%)$ \\
\hline \multicolumn{5}{|l|}{ Diagnoses leading to pain } \\
\hline Nerve injury (neuropathic pain) & 6 & & & \\
\hline $\mathrm{S} / \mathrm{P}$ abdominal surgery & 1 & & & \\
\hline Dermatomyositis (myalgia) & 1 & & & \\
\hline \multicolumn{5}{|l|}{ Opioid analgesics and dosages } \\
\hline Morphine $60-120 \mathrm{mg} / 24 \mathrm{~h}$ & 4 & & & \\
\hline Oxycodone $15-30 \mathrm{mg} / 24 \mathrm{~h}$ & 2 & & & \\
\hline Hydromorphone $24 \mathrm{mg} / 24 \mathrm{~h}$ & 1 & & & \\
\hline Codeine $240 \mathrm{mg} / 24 \mathrm{~h}$ & 1 & & & \\
\hline
\end{tabular}

*Pain is rated on a scale from 1 to 10 , in which 1 is the least painful and 10 is intolerable.

concerns raised by the Federation of State Medical Boards and greatly simplifies taking a focused history, performing a focused physical examination, making decisions with which the patient is informed and compliant, and documenting complex medication schedules. The clinician can elect to use the program only for patients taking higher doses of opioids or for patients with a history of drug dependency.

The history sheet (Figure 4) summarizes the most important elements of the patient's history, physical findings, initial laboratory and radiographic findings, and adjuvant and nonmedical (exercise, behavioral, and relaxation) treatments for pain. The contract for long-term use of opioid medication (Figure 2) serves as an educational tool for the patient. The office management guidelines (Figure 3) for opioid analgesics are printed on the back of the contract. Two copies of the office management guidelines and the contract are prepared at checkout, one to give to the patient and one to give to the pharmacist.

The flow sheet (Figure 5) records date of visits, total drug dose for 24 hours, exact amounts prescribed, date of next visit, pharmacy, peak pain scores and response to medication, hours of pain during sleep in 24 hours, hours of pain during work or useful activity during the day, minutes each day spent in exercise or relaxation (meditation, prayer), patient's view of quality of life, contact with family or friends, reliability of keeping appointments, any adverse effects (intoxication, illegal acts, adverse physical effects), laboratory findings (hepatic, renal functions if taking opioids combined with acetaminophen or NSAID), and comments.

My experience in treating chronic noncancer pain with opioid medications has been very favorable (Tables 3 and 4). All patients have achieved some relief from pain, and most have been able to 


\section{Office Guidelines for Opioid Analgesic Use in Chronic Pain}

1. There must be honest communication among physician, patient, pharmacist, and office staff.

2. Appointments should be scheduled in a fashion that is timely enough to meet the patient's need for pain control (eg, appointments for acute pain will be needed at times) and to refill medications when the patient returns for a regularly scheduled visit. The patient and physician will work out the exact supply of medication needed before the next scheduled visit, but unless the visit is scheduled before that supply is exhausted, the patient will often telephone for refills (to be avoided whenever possible). The physician will need to arrange the date of follow-up visits personally for certain patients.

3. Patients need to understand that only one physician will prescribe opioid analgesics for them and that they need to fill these prescriptions at only one pharmacy. An opioid analgesic contract is often used to emphasize this concept. The contract might need to be modified at subsequent visits, but it cannot be modified by telephone. The signed opioid analgesic contract should be copied twice, with a copy of these guidelines printed on the back of the contract before the patient leaves the office. One copy of the contract goes to the pharmacy; one copy goes with the patient; the original stays in the patient's chart.

4. Prescriptions that are lost or used too quickly should not be filled by any physician on call who does not normally see the patient. Although opioid analgesic withdrawal is unpleasant, it is usually not dangerous. The most common problem to develop when a patient runs out of pain medication is that the pain will become worse. In some cases it is useful for patients to stop taking opioid analgesics for a few days to assess whether these medications are still required or whether other methods of pain control are adequate.

5. The physician needs to know as soon as possible when patients are rude, impatient, or excessively demanding to office staff. This information is important to discuss with the patient at the next opportunity. Our practice might need to terminate our care of certain patients who are dishonest or whose behavior is too disruptive.

6. We will not be able to telephone in refills for opioid analgesic medications outside the Vermont-New Hampshire area.

7. Patients might be asked to provide blood or urine specimens from time to time. Blood tests are useful to monitor for toxicity from acetaminophen (eg, when taking Percocet and Lortab) or from nonsteroidal anti-inflammatory medications. Urine tests are used to ensure that patients are actually taking medications being prescribed.

8. Any illegal activities related to opioid analgesic use (selling doses of medications, distributing them to others, altering or forging prescriptions, etc) are grounds for immediate dismissal from the practice.

Figure 3. Office guidelines for opioid analgesic use in chronic pain. 
Table 4. Characteristics of Patients in a Primary Care Practice Who Use Opioid Analgesics for Treatment of Noncancer Pain, by Age.

\begin{tabular}{lcccc}
\hline $\begin{array}{l}\text { Patient Distribution } \\
\text { by Age }\end{array}$ & Number of Patients & Duration of Use & $\begin{array}{c}\text { Office Visits per Year } \\
\text { per Patient }\end{array}$ & $\begin{array}{c}\text { Expected } \\
\text { Visits per Year }\end{array}$ \\
\hline $20-40 \mathrm{y}$ & 9 & $6 \mathrm{mo}-14 \mathrm{y}$ & 10.5 & $2-3$ \\
$40-60 \mathrm{y}$ & 12 & $1 \mathrm{y}-17 \mathrm{y}$ & 10.3 & $3-4$ \\
$>60 \mathrm{y}$ & 9 & $6 \mathrm{mo}-12 \mathrm{y}$ & 5.5 & $4-5$ \\
\hline
\end{tabular}

Note: Total practice population approximately 3000 . Number who have averaged at least one dose of opioid analgesic medication per 24 $h$ for at least 3 months: 30 ( 1 percent)

function at a level necessary to continue with employment, family responsibilities, and religious and community activities. In no cases has treatment of pain with opioid analgesics led to psychoactive substance abuse disorders involving prescribed or illegal drugs. In the past 20 years in practice, 6 patients have been dismissed for behavior (usually manifested within 6 months or less) consistent with abuse-overdosing (becoming sedated), diverting controlled medications, or using multiple providers for prescriptions (most common problem).

In a population of approximately 3000 patients who regard me as their primary care provider, I have 30 patients who have averaged at least one dose of opioid medication per day for longer than 6 months. These patients comprise roughly 1 percent of my patient population, but the frequency of their visits on average is much higher than an age-matched control group (Table 4). The recent introduction of the contract, office guidelines, and history and flow sheets has reduced this frequency.

The decision to treat chronic pain with opioid medications is made in concert with the patient after effective pain control has proved impossible with other measures. Many patients remember a good response to short courses of opioid therapy after surgery or previous injury. Indeed, many patients return from care by a surgical specialist with unresolved pain after one or several surgical procedures. Good communication and collaboration between surgical and primary care specialists regarding short- and long-term postoperative pain management are important. Further work to improve this process is needed in many medical communities.

Patients are expected to receive all of their primary care through my office once they are enrolled as regular patients. In most cases this re- quirement has helped make management of pain one component of the management of several chronic medical problems. It is made clear to patients that (schedule IV and III) opioid medications cannot be prescribed by telephone outside the service area (a radius of roughly 70 miles), and in no case can the prescriptions be filled in states where I am not licensed. These restrictions have limited the tendency for patients to migrate to my practice specifically for the purpose of obtaining opioid prescriptions.

It has been helpful to examine certain characteristics of patients taking opioid analgesics (Table $3)$. Of the 30 patients, 7 are in the mild pain (WHO step 1) group, 15 patients are in the moderate pain (WHO step 2) group, and 8 patients are in the severe pain (WHO step 3) group. Many patients in the step 1 and 2 groups prefer mild opioid analgesics because of a history of gastrointestinal side effects or allergy to NSAIDs. Plain propoxyphene has been particularly helpful in elderly step 1 patients for this reason.

The duration of treatment for these 30 patients has ranged from 6 months to 17 years. Patient ages range from 26 to 92 years. In the step 1 group patients' age averaged 61 years compared with step 2 and 3 group patients, whose ages averaged 48 and 49 years, respectively. A greater percentage of patients in the mild pain group have additional medical and psychologic problems requiring treatment (most likely reflective of their older average age). Neuropathic pain from injury was the most common diagnosis leading to pain in the severe pain group. Selection and dose ranges of the opioid medications seem consistent with current published guidelines.

In many cases patients started opioid analgesic treatment before coming to my practice. I have started patients on opioid analgesics, and other 


\section{Opioid Analgesics for Noncancer Pain - History Sheet}

Name: Date of birth:

Diagnosis(es):

Date of pain onset:

Today's date

Pertinent history and physical findings

Laboratory and radiograph results:

Consultations \& dates:

Current habits or conditions affecting healing (smoking, alcohol, diet, etc.):

History of substance abuse:

Previous opioid analgesic use:

Opioid analgesics used now and dose:

Date opioid analgesics were started: Opioid analgesic contract date:

Adjunct pain medication:

Nonmedical treatments (physical therapy, behavioral, relaxation) :

Other important medical problems and medications

Social support (family, friends):

Education:

Occupation:

Religious and community activities:

Leisure pursuits and interests:

Comments:

Figure 4. Opioid analgesics for noncancer pain - history sheet. 
patients have stopped taking opioid medications, left the area, or died of their underlying diseases. No patient has died as a result of the opioid therapy itself, and no patient has suffered serious morbidity from withdrawal. In general, patients and their families have been pleased with the effects of opioid therapy, and the patients' functional levels have been less compromised by pain than with other treatment approaches.

The simple scale of rating pain from 1 (mildest) to 10 (agonizing - most severe pain ever experienced) has been easiest for patients to understand and has made quantifying the effectiveness of therapy the simplest. ${ }^{2}$ Patients who reported pain between 4 and 6 were considered candidates for opioid therapy, particularly if existing treatment with NSAIDs and other measures was ineffective. Patients reporting pain between 7 and 10 were definitely able to benefit from opioid therapy for effective pain control.

The goals of using opioid medications and all other components of a pain management program (eg, tricyclic antidepressants and other adjuvant medications, behavioral and relaxation therapy, exercise) have been to reduce pain and to improve patient function and quality of life while whatever possible natural healing takes place. The goal has not been to stop the addicting medicines as soon as possible. Pain has a tremendous adverse impact on patients' ability to order their lives. Because their informed participation has been essential in developing a safe and effective program, much education, discussion, and negotiation has been required. To arrive at a stable program of pain control most often has taken several months. The patient's clinical condition has sometimes changed, necessitating further modifications in their pain control program. If a patient has had an effective pain management program before coming to my practice, it has been best to maintain that program until rational changes can be agreed on between clinician and patient.

Using currently recommended doses for moderate to severe pain for several months to several years can be expensive (Tables 1 and 2). Long-acting preparations of oxycodone and morphine (in tablet form) and fentanyl (patches) reduce the total number of pills that patients must consume and avoid the high and low blood levels that the shorter acting medications produce. None of these medications is available in generic form, however, and the high cost of these preparations is a serious problem for patients and third parties who pay prescription costs for their beneficiaries.

There is a specialty pain treatment facility at the tertiary care hospital in our community, which is staffed by 3 fully trained anesthesiologists and 2 fellows. Appointments are scheduled for 1 or 2 physicians to see patients 5 days a week, with an average wait for a new patient of 1 month. Invasive treatments available at this pain treatment center include nerve blocks, injections of intrathecal opiates, anesthetics and anti-inflammatory medications, and implantable nerve stimulators. Referrals to this facility come most frequently from neurosurgeons, followed by orthopedic surgeons and primary care physicians.

The program director's preference is to provide consultation for pain management and invasive treatment as appropriate, but the day-to-day care of that patient remains the responsibility of the primary care physician. This approach would logically require that the primary care physician prescribe analgesics, but in certain cases the pain treatment program physicians are willing to assume the responsibility for opioid prescriptions for patients who live locally. To clarify this responsibility, the program director insists on effective communication at both ends of the referral and consultation process. A directory of pain treatment facilities is available through the American Pain Society, 4700 W Lakeview Ave, Glenview, IL 60025-1485.

Laine and Davidoff ${ }^{21}$ have published an article pointing out the many benefits of practicing patient-centered medicine; Woolf ${ }^{22}$ has made a compelling case for letting the patients make a well-informed decision about which form of treatment is best for their unique situation; and Leplege and Hunt $^{23}$ have highlighted that the patient is the only person who can determine his or her quality of life. There is no other issue in primary care where these factors are more important than in the relief of pain.

Primary care physicians are often fortunate to enjoy strong therapeutic relationships with their patients for a long time. Accordingly, primary care providers, perhaps more than any other specialists, are in a uniquely qualified position to provide care to patients suffering from chronic pain. Nearly all patients in this treatment group have expressed gratitude for being listened to and al- 


\section{Opioid Analgesics for Noncancer Pain Flow Sheet}

Patient name:

Diagnosis:

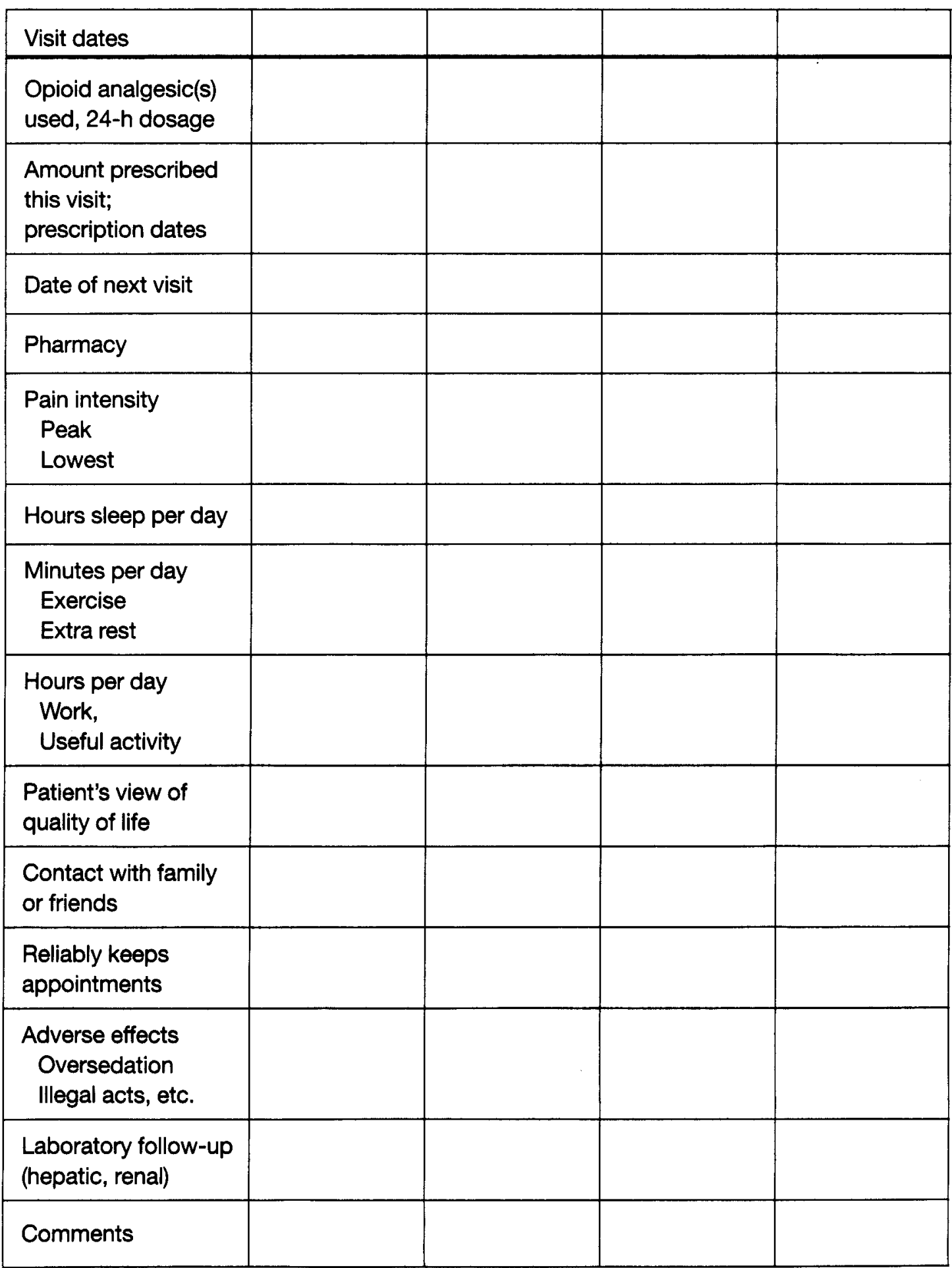

Figure 5. Opioid Analgesics for Noncancer Pain Flow Sheet. 
lowed to participate in decisions about which treatments work the best for them.

\section{Conclusion}

Opioid medications can be an important part of a safe and effective program to treat noncancer pain in a primary care office. Instances of substance abuse are no more frequent in this population than in the general patient population. ${ }^{19}$ Guidelines developed for treating chronic cancer pain can easily be adapted to patients with chronic noncancer pain. Patients with moderate to severe pain can challenge a busy primary care physician. A simple flow sheet can highlight important clinical issues and establish guidelines and expectations for patients, clinicians, office staff, pharmacists, and regulatory agencies. This flow sheet can assist in meeting these challenges and thus allow clinicians to fulfill one of their highest ethical responsibilities.

\section{References}

1. Gureje O, Von Korff M, Simon GE, Gater R. Persistent pain and well being - a World Health Organization Study in Primary Care. JAMA 1998;280:147-51.

2. Montauk SL, Martin J. Treating chronic pain. Am Fam Physician 1997;55:1151-60,1165-6.

3. Jadad AR, Browman GP. The WHO analgesic ladder for cancer pain management. Stepping up the quality of its evaluation. JAMA 1995;274:1870-3.

4. Quality improvement guidelines for the treatment of acute pain and cancer pain. American Pain Society Quality of Care Committee. JAMA 1995;274: 1874-80.

5. Cleeland CS, Gonin R, Hatfield AK, Edmonson JH, Blum RH, Stewart JA, et al. Pain and its treatment in outpatients with metastatic cancer. $\mathrm{N}$ Engl J Med 1994;330:592-6.

6. Hill CS Jr. When will adequate pain treatment be the norm? JAMA 1995;274:1881-2.

7. Brown RL, Fleming MF, Patterson JJ. Chronic opioid analgesic therapy for chronic low back pain. J
Am Board Fam Pract 1996;9:191-204.

8. Brown RL, Patterson JJ, Rounds LA, Papasouliotis $O$. Substance abuse among patients with chronic back pain. J Fam Pract 1996;43:152-60.

9. Acute pain management in adults: operative procedures. Agency for Health Care Policy and Research. Am Fam Physician 1992;46:128-38.

10. Levy MH. Pharmacologic treatment of cancer pain. N Engl J Med 1996;335:1124-32.

11. Stein C, Comisel K, Haimerl E, Yassouridis A, Lehrberger K, Herz A, et al. Analgesic effect of intraarticular morphine after arthroscopic knee surgery. N Engl J Med 1991;325:1123-6.

12. Basbaum AI, Levine JD. Opiate analgesia. How central is a peripheral target? N Engl J Med 1991;325: $1168-9$.

13. Stein $\mathrm{C}$. The control of pain in peripheral tissues by opioids. N Engl J Med 1995;332:1685-90.

14. Integration of behavioral and relaxation approaches into the treatment of chronic pain and insomnia. NIH Technology Assessment Panel on Integration of Behavioral and Relaxation Approaches into the Treatment of Chronic Pain and Insomnia. JAMA 1996;276:313-8.

15. Drugs for pain. Med Lett Drugs Ther 1993;35:1-6.

16. Average wholesale price. In: Drug Topics Red Book. New York, Topics Publishing, 1997.

17. Physician's desk reference companion guide. Montvale, NJ: Medical Economics, 1998.

18. Miller N, Gold M. Management of withdrawal syndromes and relapse prevention in drug and alcohol dependence. Am Fam Physician 1998;58:139-46.

19. Cooper JR, Czechowicz DJ, Peterson RC, Molinari SP. Prescription drug diversion control and medical practice. JAMA 1992;268:1306-10.

20. Demott K. State boards asked to ease off opioid use investigations. Fam Pract News 1998; July 15:1, 5.

21. Laine C, Davidoff F. Patient-centered medicine. A professional evolution. JAMA 1996;275:152-6.

22. Woolf SH. Shared decision-making: the case for letting patients decide which choice is best. J Fam Pract 1997;45:205-8.

23. Leplege A, Hunt $S$. The problem of quality of life in medicine. JAMA 1997;278:47-50. 